\title{
PERANCANGAN SISTEM DATA PESERTA DIDIK DAN ADMINISTRASI PADA YAYASAN ULIN NUHA
}

\author{
Iqbal Muchtaril Izzi ${ }^{1}$, Maria Cleopatra ${ }^{2}$, Noor Komari Pratiwi ${ }^{3}$ \\ 1,2,3 Universitas Indraprasta PGRI \\ Jl. Raya Tengah No. 80, Kel. Gedong, Kec. Pasar Rebo, Jakarta Timur13760, Jakarta \\ 1qubal.muchtaril@gmail.com, ${ }^{2}$ mariacleopatra1313@gmail.com, ${ }^{3}$ noorkomaripratiwi01@gmail.com
}

\begin{abstract}
ABSTRAK
Kurangnya penyajian aplikasi yang mempermudah staf administrasi dalam mengolah data peserta didik dikarenakan sistem yang digunakan dalam pengolahan data masih berupa Microsoft Office yang meliputi Microsoft Word dan Microsoft Excel, sehingga kinerja staf dalam mengerjakan sebuah administrasi membutuhkan waktu yang cukup lama. Oleh karena itu, tujuan dari penelitian ini adalah untuk membangun sistem data peserta didik dan administrasi pada Yayasan Ulin Nuha. Sistem ini dibangun untuk mengelola data administrasi yayasan dan dapat mempermudah dalam pembuatan laporan tentang pengelolaan administrasi peserta didik. Pada penelitian ini menggunakan metode grounded (grounded research) yaitu metode penelitian berdasarkan pada fakta. Dalam pengambilan data, penulis melakukan klasifikasi, pengolahan, dan analisis data yang dibutuhkan. Alat perancangan sistem yang digunakan untuk membangun sistem ini adalah diagram Konteks, diagram Nol dan diagram Rinci. Dapat disimpulkan, sistem data yang dirancang ini mempermudah pekerjaan staf Yayasan Ulin Nuha.
\end{abstract}

Kata Kunci: Sistem Data, Peserta Didik, Administrasi

\begin{abstract}
The lack of presentation of applications that make it easier for administrative staff to process student data is because the system used in data processing is still in the form of Microsoft Office which includes Microsoft Word and Microsoft Excel, so that the performance of staff in doing an administration takes a long time. Therefore, the purpose of this research is to build a student data system and administration at the Ulin Nuha Foundation. This system was built to manage the administrative data of the foundation and can make it easier to make reports on the administrative management of students. In this study using the grounded method (grounded research), which is a research method based on facts. In collecting data, the writer performs the classification, processing, and analysis of the required data. System design tools used to build this system are Context diagrams, Zero diagrams and Detailed diagrams. It can be concluded that the designed data system makes the work of the staff of the Ulin Nuha Foundation easier.
\end{abstract}

Key Word: Data Systems, Students, Administration

\section{PENDAHULUAN}

Penggunaan teknologi di segala bidang telah berkembang untuk memberikan kinerja yang lebih cepat bagi manusia. Perkembangan teknologi informasi saat ini tidak hanya digunakan untuk instansi berskala besar, namun dapat digunakan oleh berbagai kalangan masyarakat untuk menunjang suatu bisnis, organisasi, maupun usaha yang dikelolanya. Salah satu contoh saat ini adalah perkembangan informasi dalam sebuah organisasi (Louis \& Ikram, 2016).

Yayasan Ulin Nuha adalah yayasan yang bergerak di bidang sosial dan Pendidikan Anak Usia Dini (PAUD). Dalam pengolahan data peserta didik dan administrasi, Yayasan Ulin Nuha masih belum menggunakan aplikasi khusus. Dalam hal ini, pihak yayasan masih menggunakan Microsoft Office (Microsoft Word dan Microsoft Excel) bahkan terkadang masih menggunakan pencatatan secara manual dengan menggunakan buku atau lembaran kertas. Hal ini menyulitkan petugas untuk memberikan informasi secara lengkap dan akurat. Pencarian data masih dilakukan secara manual. Pengelolaan administrasi yang tidak efektif dapat menyebabkan beberapa masalah. Selain itu, pencarian data tidak dapat dilakukan secara cepat dan akurat.

Dengan adanya permasalahan ini, diperlukan sebuah sistem secara komputerisasi untuk pengolahan data peserta didik dan administrasi Yayasan Ulin Nuha. 
Perancangan sistem adalah suatu fase yang memerlukan keahlian perancangan untuk elemen-elemen komputer yang menggunakan sistem yaitu pemilihan peralatan dan program komputer untuk sistem yang baru (Agusli \& Irawan, 2019). Aplikasi berbasis desktop merupakan teknologi berbasis komputer yang berguna untuk memberikan kemudahan dalam mengelola data sehingga mampu menghasilkan sebuah laporan yang cepat, tepat dan akurat (Kurniawan \& Syahputra, 2018).

Administrasi merupakan usaha dan kegiatan yang berkenaan dengan penyelenggaraan kebijaksanaan untuk mencapai tujuan (Shiddiq \& Pradnya, 2013). Yayasan adalah badan hukum di bawah pimpinan suatu badan pengurus dengan tujuan sosial dan tujuan tertentu yang legal (Simamora, 2012). Peserta didik adalah sebagai suatu komponen masukan dalam sistem pendidikan, yang selanjutnya di proses dalam proses pendidikan, sehingga manusia yang berkualitas sesuai dengan tujuan pendidikan nasional (Jaja et al., 2018).

Berdasarkan penjelasan di atas, pada penelitian ini dirancang sistem data peserta didik dan administrasi pada Yayasan Ulin Nuha yang dapat berguna untuk mengelola data administrasi Yayasan, serta dapat mempermudah dalam memberikan laporan tentang pengelolaan administrasi peserta didik pada Yayasan Ulin Nuha.

Hal ini sesuai dengan hasil penelitian relevan yang berjudul Perancangan Sistem Informasi Pengolahan Administrasi Keuangan Sekolah Menengah Pertama Islam Terpadu Garut, dalam Jurnal Sistem Informasi yang ditulis oleh Sandika Adi Nugraha dan Ridwan Setiawan. Penelitian ini memiliki tujuan dalam pengolahan administrasi keuangan Sekolah Menengah Pertama Islam Terpadu Garut agar menjadi lebih efektif, sehingga para staf tidak mengalami kesulitan dan keterlambatan dalam penyajian data yang diminta. Perbedaan dalam penelitian ini terletak pada penggunaanya, penelitian ini berbasis web sedangkan penulis berbasis desktop.
Hasil penelitian relevan lainnya yang berjudul Perancangan Sistem Informasi Panti Asuhan di Kota Padang (Panti Asuhan Bundo Saiyo Padang), terdapat pada Jurnal Momentum. Penelitian ini memiliki tujuan agar manajemen data yayasan menjadi terkomputerisasi. Perbedaan dalam penelitian penulis terletak pada penggunaan bahasa dan studi kasusnya, penelitian ini berbasis web sedangkan penulis berbasis desktop.

Berdasarkan dari kedua hasil penelitian relevan ini, dapat disintesakan bahwa pengelolaan data dan administrasi peserta didik merupakan kegiatan operasional yang membutuhkan suatu sistem komputerisasi agar memudahkan dalam menjalankan kegiatan tersebut. Hal ini sesuai dengan hasil penelitian yang mengemukakan bahwa di lembaga pendidikan, informasi mengenai peserta didik merupakan hal yang sangat penting. Sehingga, sistem informasi manajemen terkait dengan administrasi kesiswaan sangat penting untuk diperhatikan dan dikelola dengan baik (Izza \& Sari, 2019).

Sistem data peserta didik dan administrasi pada Yayasan ini memiliki kelebihan yaitu dengan menggunakan sistem administrasi ini, proses pengelolaan seluruh data pada Yayasan Ulin Nuha akan mengalami peningkatan. Hal ini disebabkan karena pengolahan data peserta didik dan administrasi pada Yayasan Ulin Nuha lebih efektif, serta dengan menggunakan sistem ini keamanan data lebih terjamin. Dalam proses pembuatan laporan dapat dilakukan dengan cepat dan akurat jika menggunakan sistem yang terkomputerisasi dengan sistem data peserta didik ini.

\section{METODE PENELITIAN}

Metode penelitian yang penulis lakukan adalah dengan menggunakan metode grounded research dan metode observasi (pengamatan). Metode pengumpulan data yang digunakan penulis adalah dengan mengumpulkan data dan informasi untuk mendukung perbaikan hasil penelitian ini antara lain: a) Studi Kepustakaan (Library Search), b) Studi Lapangan (Field Research) (Supianto et al., 2019).

Teknik observasi yaitu dengan melakukan pengamatan dan pencatatan secara langsung 
pada staf yang bertanggung jawab mencatat informasi yang masuk dan keluar pada yayasan. Tempat penelitian ini beralamat di Jl. Damai No.48 RT 06 RW 09, Kelurahan Lubang Buaya, Kecamatan Cipayung, Kota Jakarta Timur. Teknik wawancara yaitu dengan cara melakukan tanya jawab secara langsung kepada staf yayasan untuk mengetahui apa kesulitan mereka dalam mendata informasi tentang administrasi yayasan dan data peserta didik.

Teknik Perpustakaan adalah pengumpulan data dari buku atau dokumen yang berkaitan dengan perancangan dan pengelolaan aplikasi data peserta didik pada Yayasan Ulin Nuha. Bahasa pemrograman yang digunakan yaitu java. Java adalah bahasa berorientasi objek untuk pengembangan aplikasi mandiri, aplikasi berbasis internet, aplikasi untuk perangkat cerdas yang dapat berkomunikasi lewat internet/jaringan komunikasi dan merupakan bahasa pemrograman yang dikembangkan dari bahasa pemrograman $\mathrm{C}++$, bahasa pemrograman ini seperti bahasa pemrograman $\mathrm{C}++$ (Haryanto, 2011).

NetBeans IDE yaitu sebuah lingkungan pengembangan tools untuk programmer mengkompilasi, mencari kesalahan menulis, juga menyebarkan program (Saputri \& Suwarno, 2020). MySQL adalah software yang termasuk dalam sistem manajemen basis data SQL (Database Management System) atau dikenal juga dengan DBMS yang multithread dan multi-user (Yudho \& Agus, 2014). XAMPP merupakan sebuah sistem untuk mengkoneksikan database dari beberapa program, xampp ini tugasnya sebagai server yang berdiri sendiri atau disebut juga localhost, di dalam aplikasi ini terdapat sistem yang namanya Mysql, database, penerjemah bahasa program, dan program server HTTP (Saputri \& Suwarno, 2020).

\section{HASIL DAN PEMBAHASAN}

Berdasarkan permasalahan yang terdapat pada Yayasan Ulin Nuha, penulis bermaksud memberikan alternatif pemecahan masalah yang dapat di lakukan sebagai berikut.

1. Agar informasi dapat tersampaikan dengan baik, dilakukan koordinasi serta terkomputerisasi antar sub sistem, serta perancangan sistem yang dapat memudahkan dalam pengolahan data peserta didik, donatur, pemasukan, pengeluaran dan pembuatan laporan.

2. Data hasil pengerjaan sebaiknya disimpan dan di backup menggunakan alat penyimpanan data lainnya, agar saat terjadi kesalahan kita masih memiliki cadangan data lainnya.

Dengan dibuatnya sistem Data Peserta Didik Pada Yayasan Ulin Nuha yang telah terkomputerisasi ini, dapat mempermudah proses pengerjaan dan pengecekan data khususnya pada proses pembuatan laporan dan pengolahan data peserta didik, donatur, pemasukan dan pengeluaran.

\section{Diagram Konteks Sistem yang Diusulkan}

Berikut adalah gambaran sistem yang diusulkan untuk Yayasan Ulin Nuha:

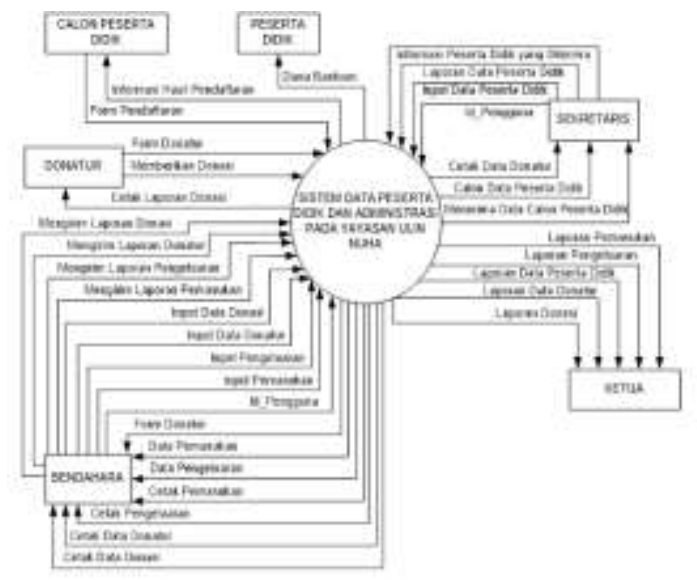

Gambar 1. Diagram Konteks Sistem yang
Diusulkan

Diagram Nol Sistem yang Diusulkan

Diagram nol merupakan gambaran proses sistem berjalan pada sistem penjualan yang menggambarkan tahap-tahap proses dari diagram konteks, sebagai berikut.

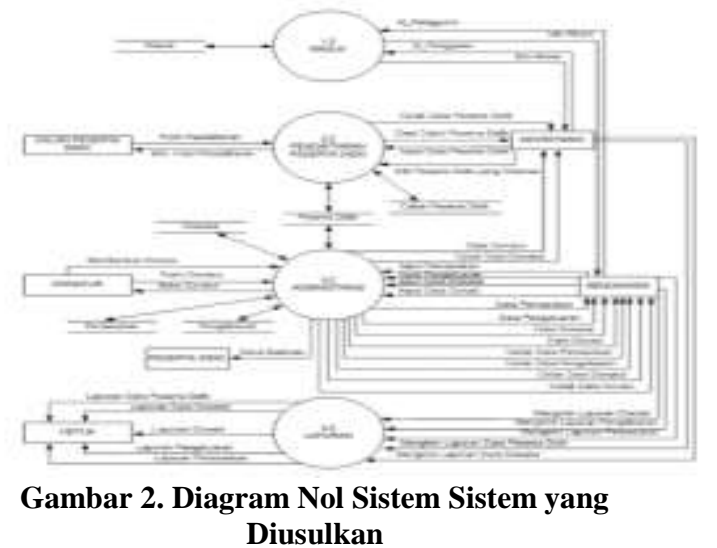




\section{Entity Relationship Diagram (ERD)}

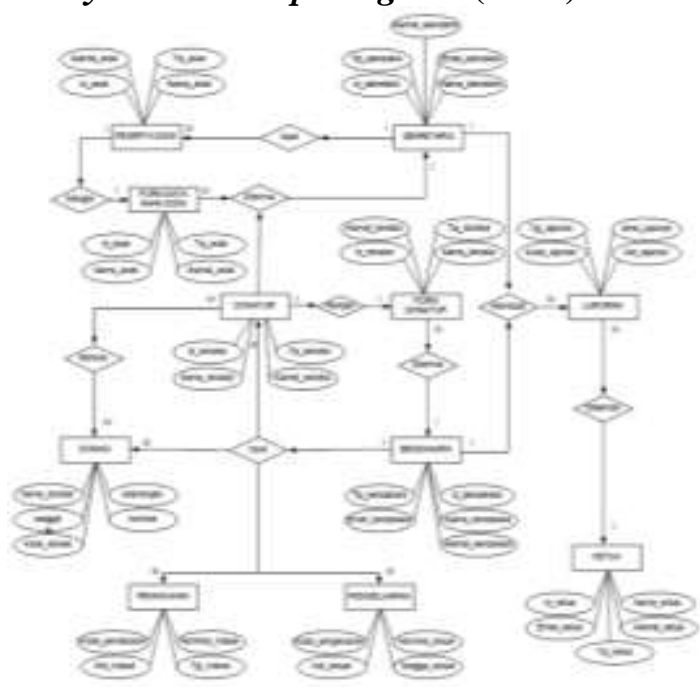

Gambar 3. ERD

\section{Normalisasi Tahap Pertama (1NF)}

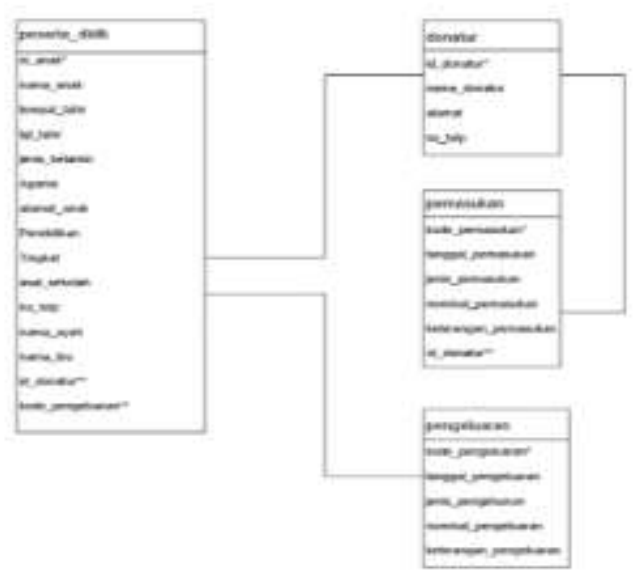

Gambar 4. Normalisasi Tahap Pertama (1NF)

\section{Normalisasi Tahap Kedua (2NF)}

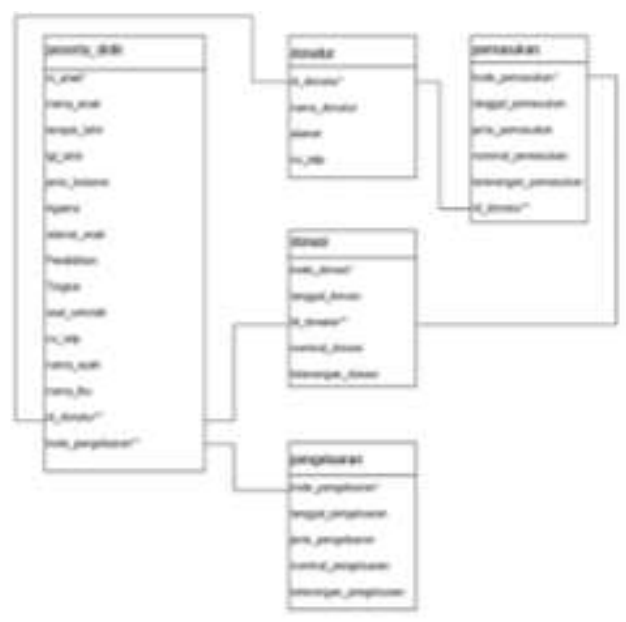

Gambar 5. Normalisasi Tahap Kedua (2NF)
Tampilan Menu Login

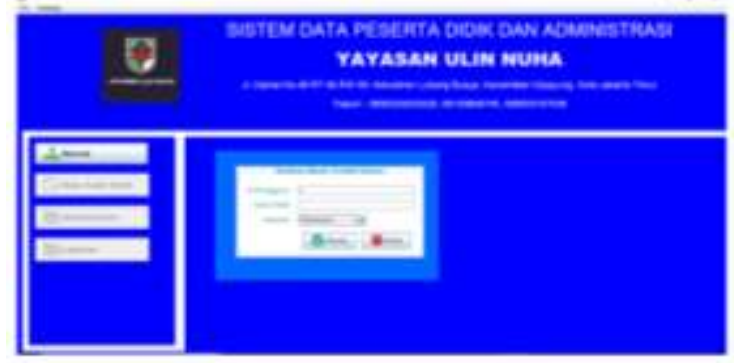

Gambar 6. Tampilan Menu Login

Pada tampilan menu login, pengguna diwajibkan untuk mengisi id pengguna, kata sandi, dan jenis jabatan. Penggunaan akun tersebut hanya dapat diakses oleh staf terkait.

\section{Tampilan Menu Utama Sekretaris}

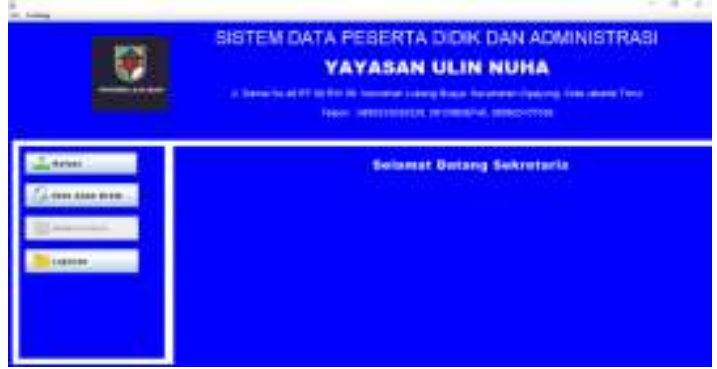

Gambar 7. Tampilan Menu Utama Sekretaris

Pada tampilan menu utama sekretaris, terdapat menu data peserta didik dan menu laporan.

\section{Tampilan Menu Data Bendahara}

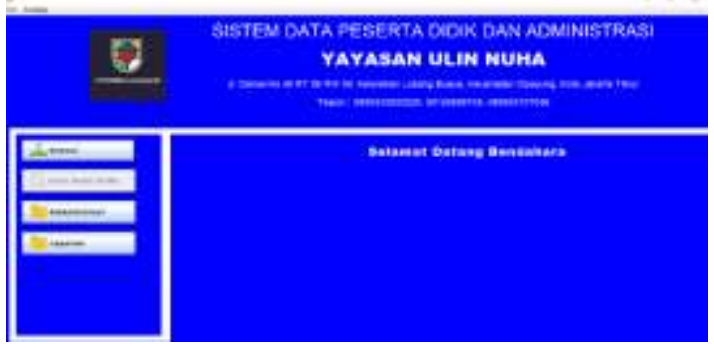

Gambar 8. Tampilan Menu Utama Bendahara

Pada tampilan menu utama bendahara, terdapat pilihan menu administrasi dan menu laporan.

\section{Tampilan Menu Data Peserta Didik}

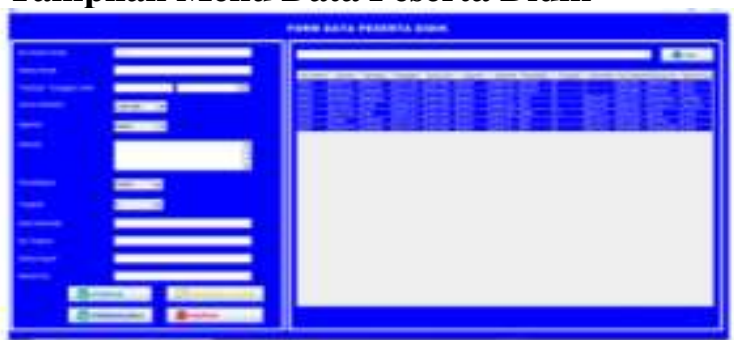

Gambar 9. Tampilan Menu Data Peserta Didik 
Pada menu data peserta didik, akses berupa penambahkan data, update data dan hapus data.

\section{Tampilan Menu Administrasi}

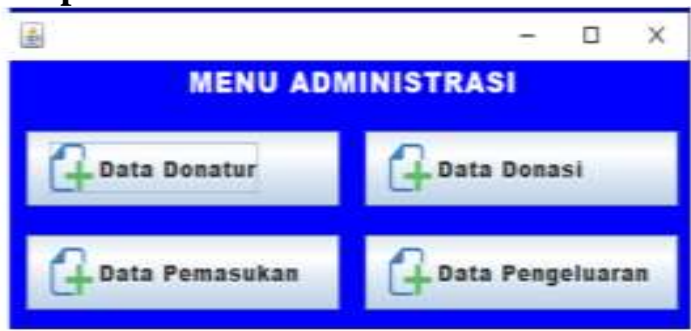

Gambar 10. Tampilan Menu Administrasi

Pada menu administrasi, terdapat pilihan menu data donatur, data donasi, data pemasukan dan data pengeluaran.

\section{Tampilan Menu Donatur}

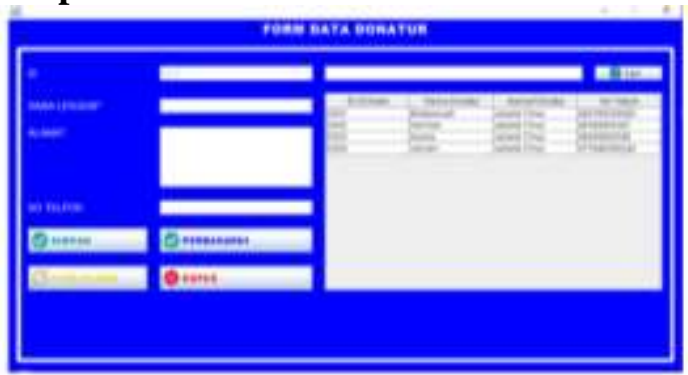

Gambar 11. Tampilan Menu Donatur

Pada tampilan menu donatur, akses berupa penambahkan data, update data dan hapus data.

\section{Tampilan Menu Donasi}

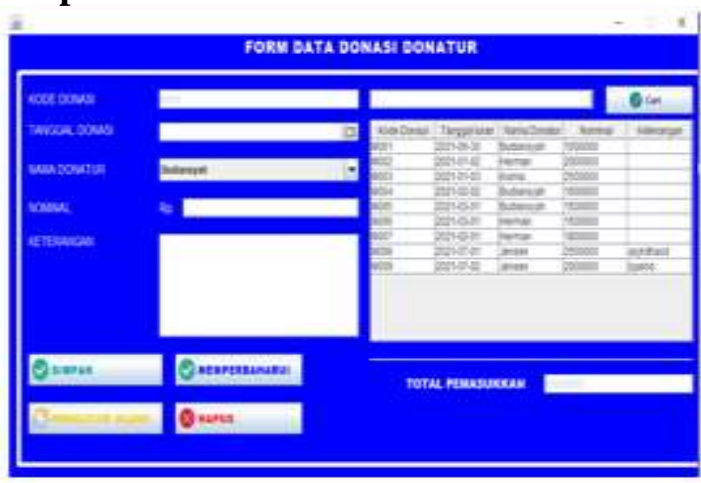

Gambar 12. Tampilan Menu Donasi

Pada tampilan menu donasi, akses berupa penambahkan data, update data dan hapus data.
Tampilan Menu Pemasukan

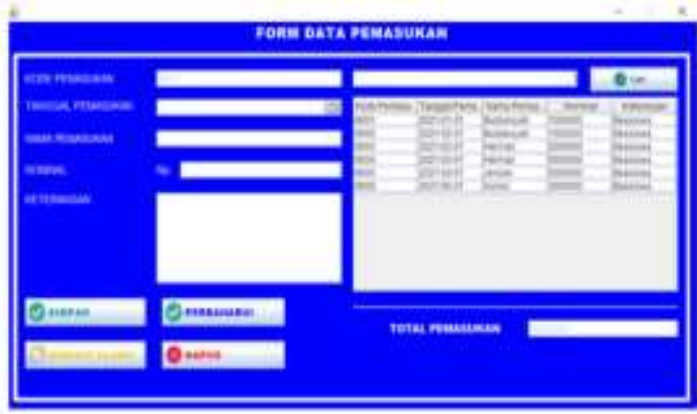

Gambar 13. Tampilan Menu Pemasukan

Pada tampilan menu pemasukan, akses berupa penambahkan data, update data dan hapus data.

\section{Tampilan Menu Pengeluaran}

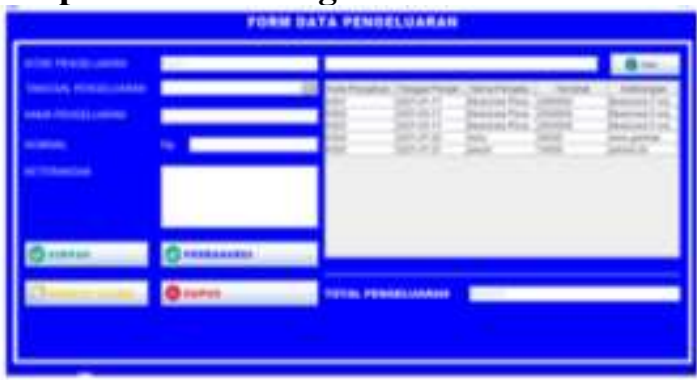

Gambar 14. Tampilan Menu Pengeluaran

Pada tampilan menu pengeluaran, akses berupa penambahkan data, update data dan hapus data.

\section{Tampilan Menu Laporan}

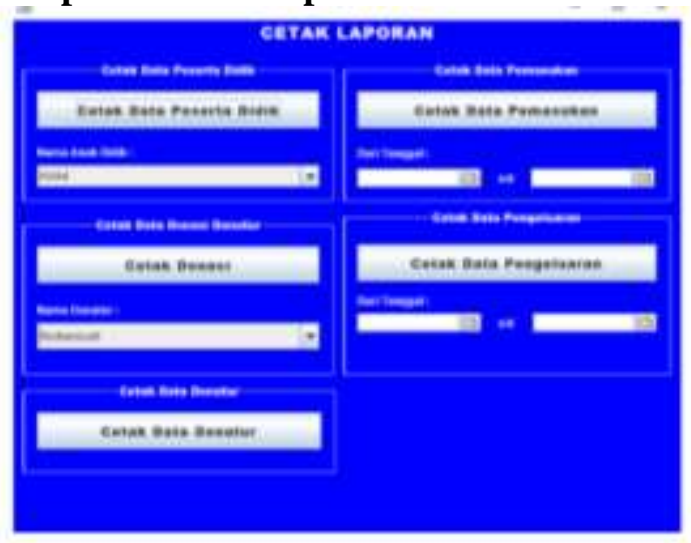

Gambar 15. Tampilan Menu Laporan

Pada tampilan menu laporan, terdapat pilihan menu cetak data peserta didik, cetak data donatur, cetak data donasi, cetak data pemasukan dan cetak data pengeluaran. 


\section{Tampilan Laporan Peserta Didik}

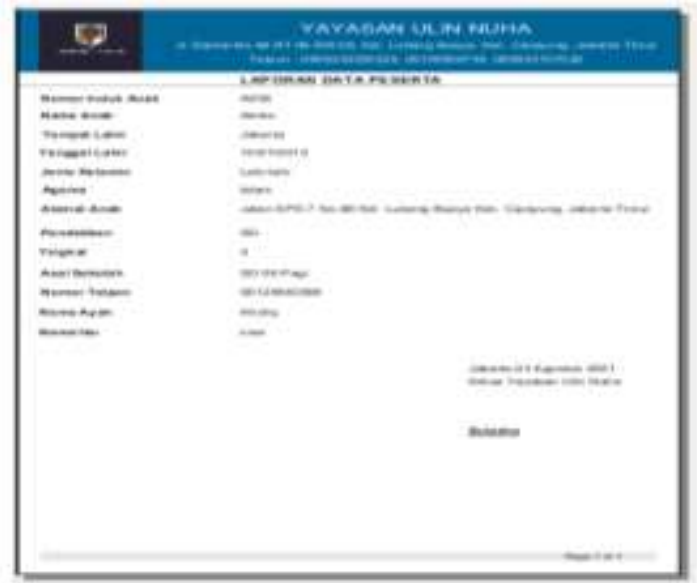

Gambar 16. Tampilan Laporan Data Peserta Didik

Tampilan laporan data peserta didik berisi data lengkap peserta didik pada Yayasan Ulin Nuha.

\section{Tampilan Laporan Data Donatur}

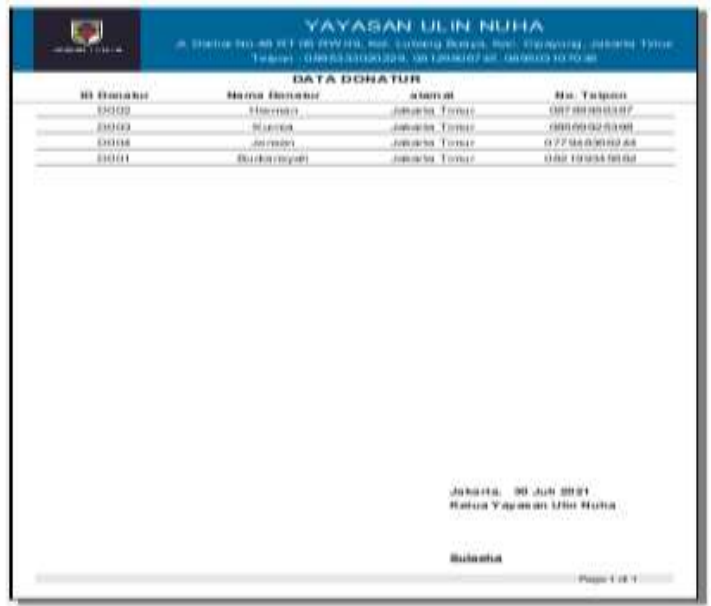

Gambar 17. Tampilan Laporan Data Donatur

Tampilan laporan data donatur berisi data lengkap donatur pada Yayasan Ulin Nuha.

\section{Tampilan Laporan Data Donasi}

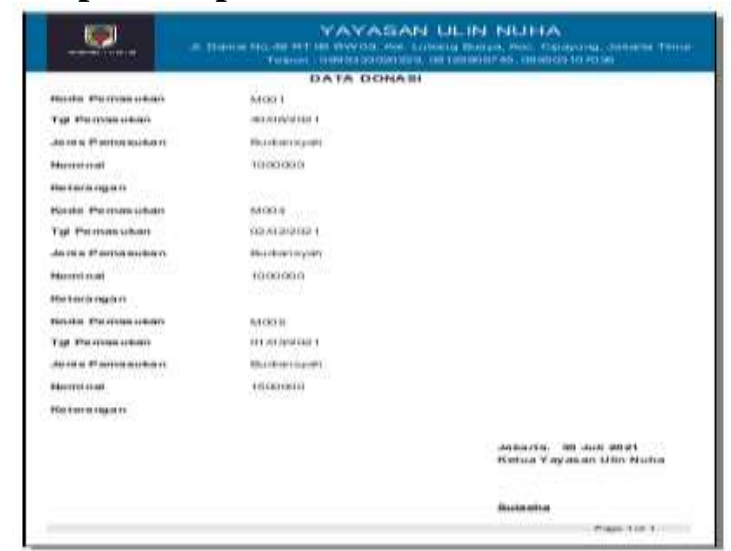

Gambar 18. Tampilan Laporan Data Donasi
Tampilan laporan data donasi berisi data lengkap donasi dari setiap donatur.

\section{Tampilan Laporan Data Pemasukan}

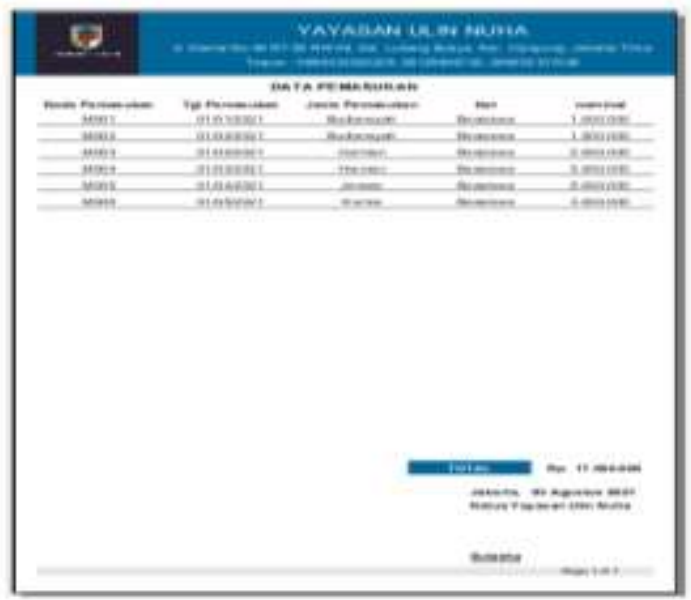

Gambar 19. Tampilan Laporan Data Pemasukan

Tampilan laporan data pemasukan berisi rincian pemasukan dana yayasan.

\section{Tampilan laporan Data Pengeluaran}

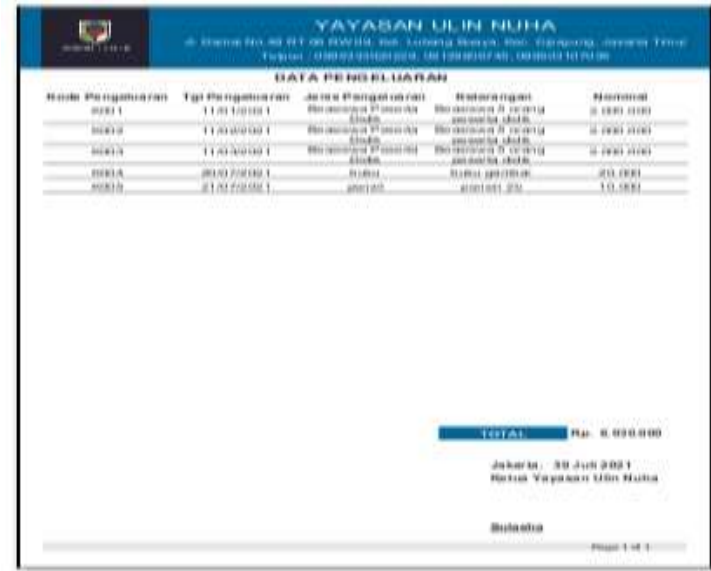

Gambar 20. Tampilan Laporan Data Pengeluaran

Tampilan laporan data pengeluaran berisi rincian pengeluaran dana yayasan.

\section{SIMPULAN DAN SARAN}

Berdasarkan penelitian yang telah dilakukan penulis mengenai sistem pengelolaan data Administrasi Peserta Didik ini dapat disimpulkan sebagai berikut: Dengan menggunakan sistem administrasi ini, proses pengelolaan seluruh data pada Yayasan Ulin Nuha mengalami peningkatan. Pengolahan data peserta didik dan administrasi pada Yayasan Ulin Nuha lebih efektif, serta keamanan data lebih terjamin. 
Proses dalam pembuatan laporan dapat dilakukan dengan cepat dan akurat. Sistem ini memudahkan sekretaris dan bendahara untuk memantau atau mengontrol data yang ada dalam database. Pengawasan terhadap pelaksanaan kegiatan lebih mudah karena adanya laporan atau informasi kegiatan yang dapat diketahui setiap saat bila dibutuhkan.

Sejalan dengan sistem usulan yang penulis buat, demi tercapainya tujuan dan sasaran yang diharapkan, penulis dapat memberi saran sebagai berikut: sebelum sistem dijalankan, seluruh pihak yang terkait harus diberikan penjelasan terlebih dahulu mengenai proses kerja sistem yang akan diterapkan sehingga tidak terjadi kekeliruan. Selain itu, perlu dilakukan pelatihan penggunaan sistem terhadap personel yang terlibat dalam sistem ini agar mereka dapat mengetahui dan memahami cara kerja sistem yang baru.

Keamanan sistem perlu dijaga dengan cara mempercayakannya pada personel yang bertanggung jawab. Meskipun telah menggunakan sistem yang terkomputerisasi, ketelitian dalam menginput data perlu diperhatikan agar data yang sudah direkam (store) benar-benar merupakan salinan dari data sumber. Kecepatan dan ketepatan hasil pengolahan data ini juga membutuhkan partisipasi aktif dari pengguna sistem, terutama kedisiplinan pengguna yang melakukan kegiatan secara langsung dengan sistem yang dirancang.

\section{UCAPAN TERIMA KASIH}

Penulis mengucapkan terimakasih kepada ayah dan ibu tercinta yang senantiasa memberikan dukungan moril maupun materil sejak dalam kandungan sampai menyelesaikan di bangku perkuliahan. Penulis juga menyampaikan terimakasih kepada Ibu Dosen Pembimbing Materi dan Teknik yang telah memberikan arahan, pikiran, waktu dan tenaganya selama penyelesaian laporan tugas akhir ini.

\section{DAFTAR PUSTAKA}

Agusli, R., \& Irawan, A. (2019).

Perancangan Dan Implementasi Sistem Informasi Akademik Berbasis Android. Jurnal Sisfotek Global, 9(2), 1-5.
Pemrograman Java. Informatika

Bandung.

Izza, A., \& Sari, P. (2019). Sistem Informasi Manajemen Untuk Pengelolaan Data Administrasi Kesiswaan Di DI MA Ihya'ul Ulum Dukun Gresik. MUDIR (Jurnal Manajemen Pendidikan), 1(2), 76-88.

Jaja, J., Khoiruddin Heri, \& Hany, N. (2018). Manajemen Peserta Didik. Jurnal Islamic Education Manajemen, 3(2), 170-180.

Kurniawan, E., \& Syahputra, A. K. (2018). Perancangan Aplikasi Pemesanan Dan Pembayaran Berbasis Desktop Pada Percetakan UD. AZKA GEMILANG Menggunakan Metode Prototype. Seminar Nasional Raya, 9986(September), 105-110.

Louis, A., \& Ikram, A. M. (2016).

Perancangan Sistem Informasi Administrasi Pada Yayasan Drs. H. Syeikh Asrul Bakar Cabang Kota Jambi Berbasis Website. 43-48.

Saputri, G., \& Suwarno, J. (2020).

Perancangan Sistem Administrasi

Berbasis Desktop Pada Klinik

Sejahtera. Jurnal Ilmu Komputer, 3(1), 26-31. Http://Www.Jurnal-

Pranataindonesia.Ac.Id/Index.Php/Jik/A rticle/View/26

Shiddiq, S., \& Pradnya, W. M. (2013). Sistem Informasi Akademik Dan Administrasi SDIT Ar-Raihan Bantul. Data Manajemen Dan Teknologi Informasi (DASI), 14(4), 49-53.

Simamora, Y. S. (2012). Karakteristik, Pengelolaan Dan Pemeriksaan Badan Hukum Yayasan Di Indonesia. Jurnal Rechts Vinding: Media Pembinaan

Hukum Nasional, 1(2), 175. Https://Doi.Org/10.33331/Rechtsvindin g.V1i2.95

Supianto, S., Atikah, A., \& Marti'ah, S. (2019). Perancangan Sistem Informasi Administrasi Sekolah Pada SMK Kesuma Bangsa 1 Depok. Systematics, 1(2), 99. Https://Doi.Org/10.35706/Sys.V1i2.219 3

Yudho, Y., \& Agus, P. (2014). Toko Online Dengan PHP Dan Mysql. PT Alex Media Komputindo. Haryanto, B. (2011). Esensi-Esensi Bahasa 